\title{
SELECTION OF SOIL STRENGTH VALUES FOR THE DESIGN OF FLEXIBLE PAVEMENTS
}

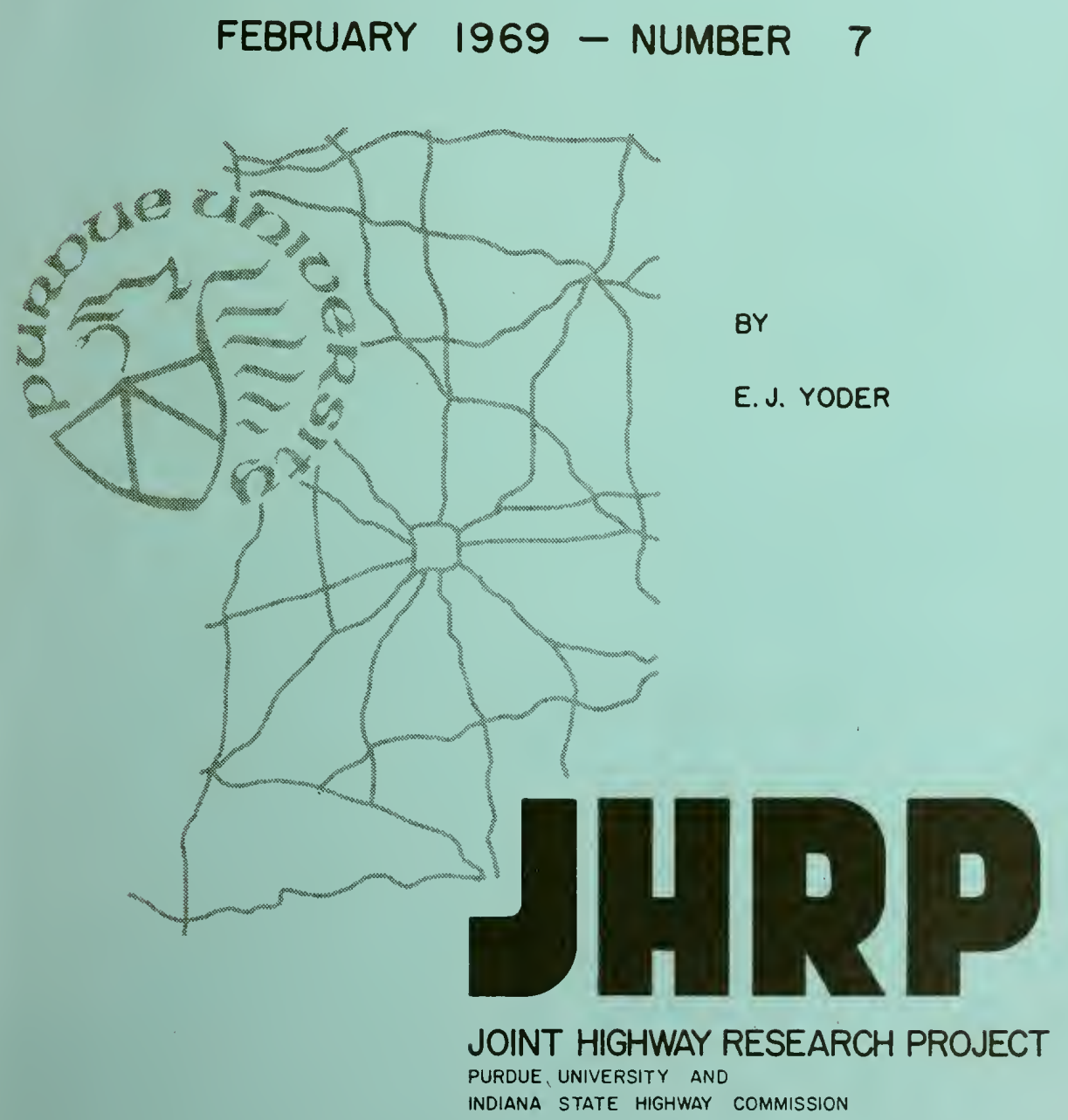




\section{SETECLION OF SOII STREAGHH VALUTS FOR THE}

DESIGN OF WLEXIBLE PAVEMARTS

To: J. F。 McLaughitin, Director

Joint Highway Research Project.

From: H, I. Michel, Associate Director

Joint Highway Researih Project
February 14, 1959

File: $6 \approx 20$

Attached is a copy or a Technical Paper titled "Selection of Soll Strength Values Por the Design of Flerible Favements. "The author is Professor I. J. Yoder of our staff. Fe paper wes presented at the 1969 Arnual Meeting of the Highsey Research Board and is programed for publication.

The paper presents a method, based on economics, for selecting a design value from an array of soil test daba for a soll area. Procedures for setting up a fleld sampling program to evaluate soli strengih on an aree basis and gridelines for zofl sampling and selection of soil strength values are presented.

The paper resulted from research by the suthor and others on the structural design of flexible peverrents. An analysis by the author resulted in developnent of a mothod presented in the paper for selecting designs strength values ror such design. The paper is presented to the Bourd for the Record and for atproval of prblication,

Respectfully submitted,

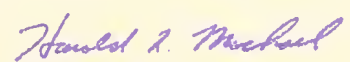

Herold Io. Michael Assoc jate Director

\section{HIS:mz}

\author{
ec: F. I. Astbancher \\ W. I. Dolch \\ W. H. Coetz \\ W. I. Grecco \\ G. K. Hallock \\ M. E. Harr
}

\author{
R. H. Harrell \\ J. A. Hevers \\ V. E. Harrey \\ G. A. Ieomards \\ F. B. Rendenhal工 \\ R. D. Miles
}

C. P. Scholer
M. B. Scott
W. T. Spencer
H. R. J. Halsh
K. B. Hoods
E. J. Yoder 
SEIECTION OF SOIX STRENGTH VAIUES FOR THI

DESIGN OF FLEXIBES PAVEMINTS

by

EIdon J. Yoder

Research Eagineer

Joint Highwey Rezerrch Froject

Digitized by the Internet Archive

in 269 f'with fanding from

LYRASIS members and Sloan Foundation; Indiana Department of Transportation

Purdue Universicy

Lafeyette, Indians

Tebruary 14, 1969

http://www.archive.org/details/selectionofsoils00yode 


\title{
DRAFT COPY - SUBJECT TO REVISION
}

SELECTION OF SOII STRENGTH VALUES FOR THE DESIGN OF FLEXIBLE PAVEMENTS

\author{
by \\ Eldon J. Yoder \\ Professor of Highway Engineering
}

Purdue University

Paper Presented

at

Highway Research Board Meeting

January $13-17,1969$ 


\section{ABSTRACT}

Recent studies of quality control, soil and material variance ruve shown that considerable variation can exist in a completed highway project. These studies have served to point out the need for developing design techniques which take into account this variation.

This paper presents a method, based on economics, for selecting a design value from an array of soil test data for a soil area. This analysis indicated that the optimum design strength value is generally, but not always, less than the mean test value and that it is dependent. upon amount of traffic, environmental conditions, soil variability, compaction variability and pavement costs.

Procedures were developed for setting up a field sampling program to evaluate soil strength on an area basis. These criteria are based on traffic that will use the road, anticipated moisture conditions in the completed subgrade and soil variance.

Guide lines for soll sampling and selection of soil strength values are presented. These guide lines are based on the factors of traffic, anticipated degree of saturation and soll variance. 


\section{SELECTION OF SOIL STRENGTH VALUES}

\section{FOR THE DESIGN OF FLEXIBLE PAVEMENTS}

by

Eldon J. Yoder

\section{INTRODUCTION}

During the past ten to twenty years a great deal has been written on the subject of the structural design of flexible pavements. By and large major effort has gone into two broad phases of the problem, namely, (I) theoretical analysis of pavement behavior and (2) empirical methods of design.

Historically, design concepts are built upon the premise that the engineer can determine "allowable stresses" for the pavement materials. This is the approach used by structural engineers and, in the case of manufactured materials such as steel, the method has given satisfactory results. However, "allowable" values for soils are difficult to specify within reasonable limits.

\section{VARIABILITY}

Even though all methods of pavement design, irrespective of assumptions of elasticity, or whether they are based upon empirical data, assume that it is possible to determine a specific design value for a given loading and climatic condition, engineers have known for a long time that a soil deposit is not "constant" but rather, test results can vary over a wide range. Recent research into quality control of highway construction $(3,10) *$ has shown that variation in the completed highway project is often much

* Numbers in parenthesis refer to reference numbers at the end of this paper. 
greater than supposed by the design engineer. Thus, it is necessary to set up procedures for accounting for variability during design. Further, research into variability of a soil's engineering properties (5) have demonstrated that there is no single test value that can be assigned to a soil deposit with any certainty. Major research effort has gone into mapping and classification of soils (11); nevertheless, methods of quantifying a given soil area has not been possible up to the present time.

The tenuous basis of assigning soil strength values is forcibly demonstrated when roads are built in new areas such as in developing countries. Here, at times neither time nor personnel permit detailed investigations and it becomes necessary for the engineer to resort to broad generalizations of his problem.

\section{STATEMENT OF THE PROBLEM}

As implied in the title, the purpose of this paper is to present a method for selecting design strength values for the design of flexible pavements. This research deals specifically with design values for subgrades although the method of analysis is believed to be applicable to all components of the paving structure.

Insofar as design is concerned, the problem resolves itself into several basic questions the design engineer must answer.

1. For a given soil type, which subgrade strength value, from a series of tests, should be selected to be representative of the soil area?

a. If an average test value is selected, it follows that about one half the project will be over-designed and the other half under-designed.

b. Likewise, if the lowest, strength value is selected, most of the structure is over-designed. 
c. Conversely, if the highest strength value is selected, a large portion of the structure will be under-designed.

2. How can construction variability (i.e., compaction, thickness, etc.) be accounted for in question No. 1 above?

3. Recognizing that under-design requires additional maintenance expenditures, what degree of under-design (or over-design) is the most economical?

4. What is the probability of structural defects occurring, and most important, what extent of distress can be tolerated both from a performance as well as an economic point of view?

Figure $I(a)$ shows a flow diagram which illustrates (in ideal form) the decision making process that the design engineer must go through in the design of a pavement structure. Figure l(b) illustrates the concept of serviceability as influenced by maintenance and time. In its simplest form, the purpose of this project was to establish a method for optimizing the decision making process in light of the variables shown to the right of Figure $I(a)$, and at the same time account for maintenance and serviceability requirements.

\section{DESIGN UNITS}

To accomplish his design, the design engineer follows two steps, he tests relatively small soll samples in the laboratory, and (2) he evaluates these laboratory data for a design area in the field.

Figure 2 shows a generalized representation of pavemert design units. The design units are generally delineated prior to sampling, although in many cases they are established during the sampling program. Further, the design units are generally finalized only after laboratory and/or field tests are made. The units are delineated on the basis of geology, pedology, known drainage conditions at the site, etc. 
Variability in soll test data will result as indicated in Figure $2(a)$. It should be emphasized that variability is a natural phenomenon. Hampton, Yoder and Burr (5) have shown that varlabllity depends upon many factors including the inherent characteristics of the soil in place, methods of sampling, method of test and many other factors.

The factor of natural variance is further compounded by construction techniques and final moisture conditions at the site as suggested in the lower portion of Figure 2. Since the design of the pavement should be based on the characteristics of the completed subgrade, it becomes necessary to account for variation in density and molsture in the subgrade.

Thus, even though design units can be determined by the geologist and soils engineer, decisions must be made relative to a specific design valke that can be assigned to the unit.

Data from many areas of the world were evaluated by the author (12) to evaluate the character of natural soil deposits. These data have indicated that the test data were generally normally distributed but that the mode (and mean values) tended to be skewed to the left within the distribution. It was also shown that (from the standpoint of strength) the variability of the completed subgrade is greater than that indicated from laboratory tests made under standard conditions because of variation of moisture content and density along the roadbed.

The pertinent conclusions reached in the study of the variance of natural soil deposits, and upon which the study reported herein is based, are summarized briefly below.

1. The distribution of test data can be approximated by the normal distribution, although many times a log-normal distribution is indicated. 
2. Variance in test data is not unique to any specif'ic test, but is considered to be a natural phenomenon controlled by the type of deposit.

3. The amount of variation of physical properties depends upon the property being measured itself

4. Care must be exercised in delineating properties of a soil swes using classification data since classification does not account for density nor moisture conditions that might exist in the completed subgrade. From the standpoint of the CBR, the variability of the completed subgrade is greater than that indicated from laboratory tests due to the variation in density and moisture that exists along the roddbed.

5. The residual'solls investigated showed somewhat more variance tran the transported soils.

6. Full reliance on pure statistics for evaluating a test area is not desirable unless some consideration can be given to known behavior of the in-place soil.

7. When considered on an area basis, tests made on the parent material as opposed to the "A" and "B" horizons are the best predictors of the subgrade that will be finaliy constructed.

8. The indicated variance in $\mathrm{CBK}$ for soaked conditions is higher trien corresponding indicated variance for samples at optimum moisture content and lower degrees of saturation.

9. To be of most use, the value which is used to define s soil area must account for construction variability and climatic effects. 
In the final analysis, it is necessary for the engineer to select a design value from the array of values that are obtained from a given design unit. Iogically, the design value that is selected must reflect minimum cost taking into account initial cost, maintenance cost, classification of the road (its intended use) and the overall economy cf the area under consideration.

\section{ASSUMPTIONS FOR ANALYSIS}

In the analysis that follows several basic assumptions were made that should be fully understood by the reader. The basic assumptions are sumrarized below:

1. It is assumed that design units can be delineated on the basis of goelogy, pedology, climate, traffic and availability of local construction materials.

2. It is assumed that the test results are normally distributed.

3. Since the strength values of the subgrade are assumed to be random over the design unit, any decision that is made regarding initial thickness of pavement must apply to the entire stretch of road under consideration.

4. The surface type and minimum thickness of surface and base course depends only upon the traffic conditions. Therefore, each traffic category is assumed to have a unique surface thickness.

5. It is assumed that the pavement will be designed for a finite life period and that major maintenance will be provided at the end of this design life period.

6. The assumption is made that in addition to major maintenance, the pavement will be maintained periodically during its design life as surface devects appear. This assumption states implicitly that if 
a low design thickness is selected, some of the road wili show distress and that this distress will be corrected sometime during the analysis period (probably just prior to resurfacing) by increasing the thickness accordingly or by appropriate patching and other maintenance procedures, and that this routine maintenance is in addition to major maintenance.

\section{Cost Analysis}

Even though CBR tests, performed in the laboratory under standard conditions, approach a normally distributed situation for a design area, the distribution of thicknesses for the same area shows little similarity to the distribution of test results (See Figure 3). The dashed curve of Figure 3 shows a typical distribution of CBR values as a function of the area whereas the solid curve shows the same distribution for thickness. The reason for the differing distribution lies in part in the CBR-thickness relationship, but is also due to variance of field compaction, as illustrated in Figure 2(b), and (c) and moisture content, as illustrated in Figure 2(d), (see reference 12).

\section{Maintenance}

Major maintenance costs (as well as serviceability) for flexible pavements are "spotty" inasmuch as they are not uniform over an analysis period but change at different specified periods during the life of the pavement (see Figure 1(b)). However, some day-today maintenance is neceesary for nearly all cases. But even though no great amount of routine day-to-day maintenance is applied to a specific road, it is generally necessary to spend more time and money on certain sections of a road than on another just prior to major maintenance. This "end of period" maintenance may consist of patching, additional thickness of resurface due to rutting, etc., removal of badly worn areas, recompaction and others. Thus, maintenance is carried 
out in two distinct steps. 1) day-to-day and/or special end-of-period maintenance, and 2) major planned maintenance.

For this study, consideration was given to the two types of maintenance mentioned above. Figure $4(a)$ shows the general relationship between age and required thickness. The first major decision that the designer must make is that regarding the age at which the pavement will be retired or resurfaced. If, as shown in the upper portion of the Figure, the designer selects a subgrade strength value equal to $C B R_{1}$ for design, the pavement will be satisfactory until age $y_{1}$. Likewise, if he selects some other design value from the array of test data from an area, the life of the pavement will vary accordingly. Often the engineer can show considerable savings in money by adopting stage construction as shown in the lower portion of Figure $4(a)$.

Referring to Figure 4 (b) assume that the curve representing required thickness as a function of percent of roadway, as determined from an array of test results, and for a given design life, is as shown in the upper portion of the Figure. If a design thickness corresponding to point $C$ is selected for design, the portion of the road from B to $C$ is under-designed whereas the amount, of road to the right of point $\mathrm{C}$ is over-designed. In the lower portion of Figure $4(\mathrm{~b})$ and for the assumption that the design value is given as point $C$, the volume of material lacking for 100 percent design would be that shown as the area $A-B-C$. If a thickness corresponding to point $A$ were selected as the design for the road, the initial cost would be high and maintenance cost would be nil. On the other hand, if the thickness corresponding to point $\mathrm{C}$ is selected for design, the initial cost is less but maintenance costs increase because of the deficient material between points $B$ and $C$. 
Figure 5 shows a typical plot of total cost (TC) as a function of percentile of roadway. Total cost here consists of initial cost (IC) and maintanance costs (M). Maintenance costs in turn include a factor for interest rates on the investment.

A least cost analysis was made by computer of a wide range of data. Primary thickness - CBR relationships used were those proposed by Turnbull, Foster and Ahlvin (9) and were checked using criteria of the Road Research Laboratory (7) and performance data from the AASHO Road Test.

Figure 6 shows the results of the above analysis. The results are given in terms of a "Cost Ratio" (CR). Cost Ratio as used herein is defined as the ratio of unit cost of maintenance to unit cost of initial construction. For example, if a pavement surface costs one dollar $(\$ 1.00)$ per square yard to construct and two dollars $(\$ 2.00)$ per square yard to patch at infrequent intervals, the Cost Ratio is equal to 2.0 .

It is to be noted specifically that the computer program was written to correct the strength values for variance in fileld compaction and that the horizontal scales of Figure 6 are for two compaction values, uniform compaction $(\sigma$ comp. $=0$ ) and variable compaction $(\sigma$ comp. $=5)$. A typical value of compaction standard deviation is considered to be five pounds per cubic foot (10). In Figure 6, the curves are for soil coefficients of variation of $10 \%, 30 \%$ and $50 \%$. The $10 \%$ value is representative of subgrades constructed from uniform deposits of wind and water laid soils, the $30 \%$ value for undifferentiated soils that will exist in the subgrade near optimum moisture content (arid and semi-arid areas) and the $50 \%$ value fur undifferentiated subgrades where the soaked value governs (see reference 12). 
Table I - Typical ranges in the maintenance to initial cost ratio (C.F.)

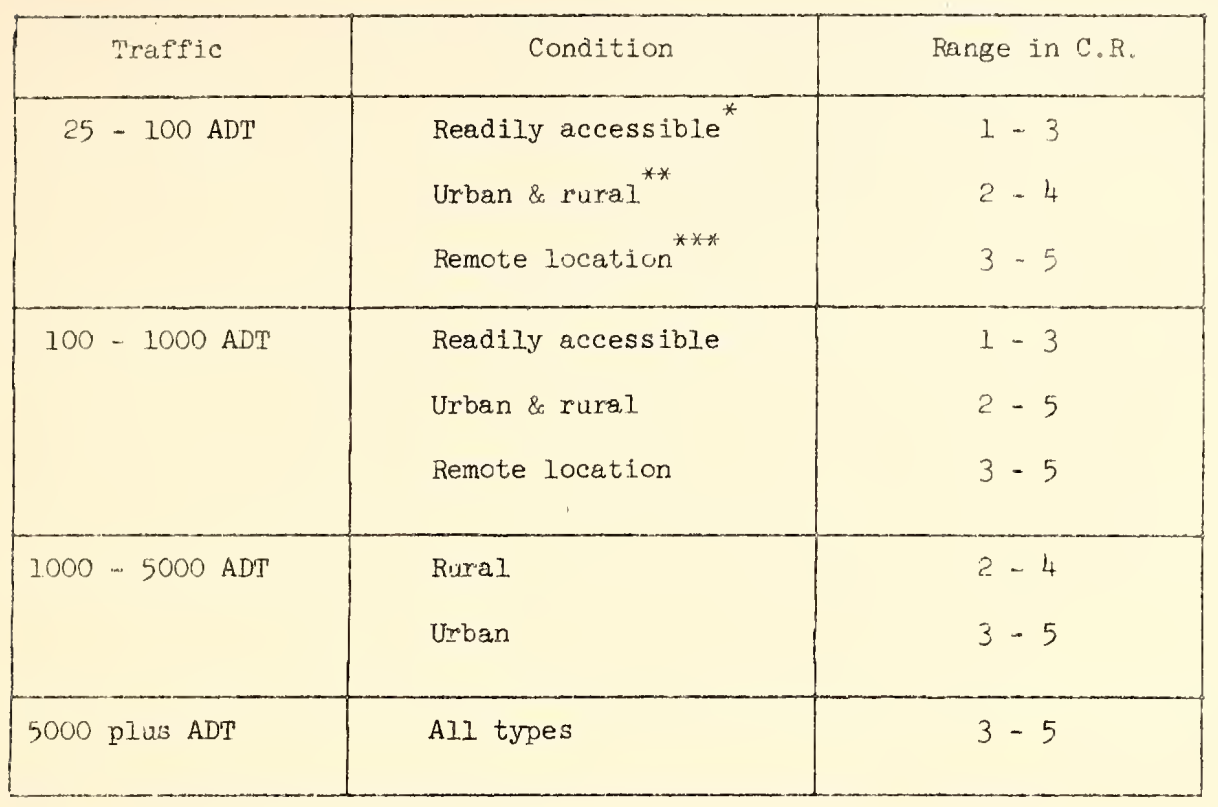

* For example, near an urban area and where detours are easily furníned

* Situations where provision of detours, etc. may be difficult

*** Locations where road is a great distance from maintenance facilities 
The same type of reasoning can be applied to high type pavements (interstate highways for example) where a shutdown to the fiacility to provide maintenance is very costly from the users standpoint and it becomes more economical to design a relatively heavy pavement that requires little or no maintenance. Likewise the cost of maintaining highways where numberous detours can be provided can be very high. General Relationship Between Mean and Design Values

Curves which relate design $\mathrm{CBR}$ and mean $\mathrm{CBR}$ for typical conditions are shown in Figure 7. From Figure 7 , if the mean CBR value is known as well as the variance of the test results and cost ratio, the design CBR for optimum cost can be read directly from the charts. It is to be noted that the charts are dependent on traffic and include a factor for variability of compaction.

Performance and Serviceability

The analysis of least cost design has indicated that some test value other than the minimum (maximum thickness) generally governs the design for a given soil area. By implication, this analysis states that some surface defects will occur and that these will be maintained as they take place. Certainly, tolerance of the driving public to these defects should also have its influence on the percentile test value selected for design.

Utimately the performance of the pavement in the field determines the adequacy of the design. One of the major contributions of the AASHO Road Test is that dealing with serviceability concepts. These were first presented by Carey and Irick (2).

There appears to be little need to discuss the concept of serviceability here since a great deal has been written on this subject in recent years. Nevertheless, it is pertinent to note that a PSI of 2.5 represents a pavement just satisfactory for Interstate Routes and a PSI of 2.0 for secondary 
pavements. Extent of cracking and patching for the acceptable serviceability levels are 30 percent and 50 percent respectively. Thus, the driving public w:ll tolerate something less than a "perfect" pavement.

\section{Sunmary}

The results of this portion of the study have illustrated that when interpreting soil test data for a design unit, the optimum test value (from the standpoint of total cost) is generally, but not always, less than the mean test value. Further, the optimum value depends upon soil test variance, field compaction variability and traffic. The soil variance is in turn influenced by the anticipated moisture conditions at the site.

Thus, in general terms it can be said that the optimum design percentile value decreases as:

1. Soil test variance increases,

2. traffic increases,

3. field compaction variability increases; and the

4. anticipated moisture content of the completed subgrade increases, and

From the standpoint of traffic and climate:

1. For low traffic roads the optimum value approaches the average value,

2. for high traffic roads the optimum value is near the minimum strength value,

3. in arid climates the optimum approaches the average value; and

4. in high rainfall climates the optimum is near the minimum value. 


\section{SOIL SAMPLING AND DESIGN}

The purpose of sampling a soil is to enable the engineer to estimate, within reasonable precision, test values prior to construction so that, the plans can be drawn up. Obviously, the degree of precision of sampling is dependent upon a number of factors including number of samples obtained, lateral and vertical position of the sample in the natural soil strata, and most important, the ability of the engineer to delineate his design units prior to the sampling program.

Since for this analysis, use has been made of percentile test values, it becomes necessary to determine the number of samples when the degree of precision of the percentile test value is given.

\section{Limit of Accuracy}

The required sampling program can be determined from the theory of small samples if the required accuracy within which the test value must be predicted from the sampling program is known. Since the object of the sampling program is to enable the engineer to predict the pavement structure rather than the test value alone, the required limit of accuracy for the test value is dependent upon the relationship between thickness (or quality) of the pavement structure and the predicted test value. In Figure 8 , assuming that the design percentile test value is known, the required design thickness $t_{2}$ can be determined from the appropriate design curve. Obviously some tolerance in the design thickness must be permitted since it is impossible to construct a pavement to an absolute uniform depth. Hence, the limits of accuracy (insofar as thickness is concerned) is shown as $t_{1}$ and $t_{3}$ in the Figure. A literature search was conducted for the purpose of estimating the variation in pavement thickness that might be expected on typical pavements. It appears that a 10 percent variation 
in flexible pavement thickness is quite common; therefore, this value kas been used in the analysis that follows although general relationships have been developed to permit selection of a value for limits of accuracy assuming tolerable variations in pavement thickness ranging from $1 \%$ to $20 \%$.

Techniques demonstrated in Figure 8 were used in conjunction with the design curves developed for this project and from these data the curves shown in Figure 9 were developed. Here, the required number of borings is given in terms of anticipated traffic and soil variation. If the com efficient of variation of the soil deposit is not known, the following can be used as a guide.

1. Undifferentiated transported and residual soils
a. Soaked CBR, C.V. $=50 \%$
b. CBR @ opt.w, C.V. $=30 \%$

2. Uniform wind and water deposits, C.V. $=10 \%$

\section{EFFECT OF VARLABIES ON SAMPLING}

It has commonly been assumed by many investigators that the required boring program is dependent only on the variability of the soil deposit. Figure 9 shows that the program is in addition to the above, dependent upon traffic and the degree of saturation (climate and environment) that is anticipated for the finished subgrade. The results of this investigation have indicated that the traffic and saturation fictors are as important as, and in many cases more important than, the soil variability factor. 


\section{GUIDE LINES FOR SAMPLING AND DESIGN}

The curves shown in Figure 9 were developed using a wide range of soil variance values and traffic conditions. The effect of the anticipated traffic upon the required sampling program is readily noted as is the effect of soil variance itself.

The guide lines that are shown in Table 2 were formulated using typical values of coefficient of variation. Here again, the effect of traffic, environment (degree of saturation) and the variability of the natural soil deposit are suggested. The marked effect of traffic on the required sampling program is noted.

Data such as shown in Table 2 are suggested only as guide lines since the required sampling program and selection of percentile test value for design can be determined with greater accuracy using the techniques presented in reference 12 for a given project. Further, use of Table 2 is dependent upon the engineer's ability to estimate initial cost, maintenance cost, anticipated traffic, molsture conditions that will prevail in the pavement structure and, most important, his ability to delineate the design unit. Use of Classification Data in Design

Classification data can be used to advantage in design using the techniques described in this paper. The soil which governs the design (percentile value) can first be delineated on the basis of soil classification data and then strength tests can be made on just this soil rather than on the complete array of samples. Results of a study into this method, although not presented here, have illustrated that very little precision is lost through the use of classification data (12). 
Table 2 Suggested Guide Lines for Soil Exploration and

Selection of Design Value for Flexible Pavements

\begin{tabular}{|c|c|c|c|c|}
\hline Item & $\begin{array}{l}\text { Undifferentiated } \\
\text { transported soils } \\
\text { (tills, clays etc.) }\end{array}$ & $\begin{array}{l}\text { Gravels } \\
\text { and } \\
\text { Sands }\end{array}$ & $\begin{array}{l}\text { Wind and } \\
\text { water } \\
\text { laid } \\
\text { soils* }\end{array}$ & $\begin{array}{l}\text { Residual } \\
\text { soils }\end{array}$ \\
\hline \multicolumn{5}{|l|}{$\begin{array}{l}\text { Low Traffic } \\
(25-100 A D T)\end{array}$} \\
\hline $\begin{array}{l}\text { Basis soaked values } \\
N^{* *} \\
\% \text { tile (low C.R.)*** } \\
\% \text { tile (high C.R.) }\end{array}$ & $\begin{array}{c}10-15 \\
30 \\
20\end{array}$ & $\begin{array}{l}5-10 \\
35 \\
30\end{array}$ & $\begin{array}{c}3-5 \\
35 \\
30\end{array}$ & $\begin{array}{c}10-15 \\
30 \\
20\end{array}$ \\
\hline $\begin{array}{l}\text { Basis opt. w } \\
N \text { tile (low C.R.) } \\
\% \text { tile (High C.R.) } \\
\% \text { tig }\end{array}$ & $\begin{array}{l}5-10 \\
35 \\
30\end{array}$ & $\begin{array}{c}3-7 \\
40 \\
35\end{array}$ & $\begin{array}{l}3 \min \\
35-50 \\
35-50\end{array}$ & $\begin{array}{l}5-10 \\
35 \\
20\end{array}$ \\
\hline \multicolumn{5}{|l|}{$\begin{array}{l}\text { Med. traffic } \\
(100-5000 \mathrm{ADT})\end{array}$} \\
\hline $\begin{array}{l}\text { Basis soaked values } \\
\text { N } \\
\% \text { tile (low C.R.) } \\
\% \text { tile (high C.R.) }\end{array}$ & $\begin{array}{c}15-25 \\
30 \\
15\end{array}$ & $\begin{array}{c}10-15 \\
35 \\
30\end{array}$ & $\begin{array}{c}3-5 \\
35 \\
30\end{array}$ & $\begin{array}{c}15-25 \\
30 \\
15\end{array}$ \\
\hline $\begin{array}{l}\text { Basis opt. w } \\
\text { N } \\
\% \text { tile (low C.R.) } \\
\% \text { tile (high C.R.) }\end{array}$ & $\begin{array}{l}7-12 \\
35 \\
20\end{array}$ & $\begin{array}{l}5-10 \\
40 \\
35\end{array}$ & $\begin{array}{l}3 \mathrm{~min} \\
35-50 \\
35-50\end{array}$ & $\begin{array}{l}7-12 \\
35 \\
20\end{array}$ \\
\hline \multicolumn{5}{|l|}{$\begin{array}{l}\text { High traffic } \\
(5000 \text { plus ADT })\end{array}$} \\
\hline $\begin{array}{l}\text { Basis soaked values } \\
\text { N } \\
\% \text { tile (low C.R.) } \\
\% \text { tile (high C.R.) }\end{array}$ & $\begin{array}{c}20-30 \\
25 \\
10\end{array}$ & $\begin{array}{c}15-20 \\
30 \\
15\end{array}$ & $\begin{array}{c}5-10 \\
30 \\
15\end{array}$ & $\begin{array}{c}20-30 \\
25 \\
10\end{array}$ \\
\hline $\begin{array}{l}\text { Basis opt. w } \\
N \text {. } \\
\% \text { tile (low C.R,) } \\
\% \text { tile (high C.R.) }\end{array}$ & $\begin{array}{c}10-20 \\
30 \\
15\end{array}$ & $\begin{array}{l}5-10 \\
30 \\
25\end{array}$ & $\begin{array}{c}3-7 \\
30 \\
25\end{array}$ & $\begin{array}{c}10-20 \\
30 \\
15\end{array}$ \\
\hline
\end{tabular}

NOTES: * Many alluvial and lacustrine deposits are highly variable. It is assumed that major solls (sand bars, slack water areas etc.) are delineated prior to sampling.

** Number of samples required.

*** Percentile test value selected for design. 
Summary

As was the case for selection of a design value, the effects of traffic and anticipated moisture conditions in the completed subgrade are striking.

Recalling that as degree of saturation decreases, the coefficient of variation decreases, the results indicate that the required number of borlings increases as:

1. Soil variance increases,

2. traffic increases; and

3. anticlpated degree of saturation increases.

\section{SUMMARY}

The primary purpose of this paper has been to present concepts relative to a method for optimizing certaln decisions the design engineer must make when establishing the design of a pavement. Perhaps the most utility of the techniques can be realized in developing areas where experience with the materials at hand are meager or completely lacking. Suggested criteria are presented (Table 2) for sampling and selection of a design value.

It has been demonstrated that the anticlpated traffic and moisture condition at the site are important factors when selecting a specific design value from a series of tests. Since the selection is controlled by the above factors coupled with construction and maintenance costs, reliable estimates of these quantities must be made for a given area. Further, it is suggested that in soll mapping and terrain analysis, the sampling program must recognize these factors.

To use this technique in a new or undeveloped area, the following steps are recommended. It is specifically noted that these steps do not preclude sampling and testing. 
1. Delineate the design unit.

2. Make an estimate of the variance of test data.

a. In the absence of specific data, the upper portion of Figure 6 can be used as a guide.

3. Determine the anticipated moisture conditions (soaked, dry, etc.)

4. Establish the number of random samples using Figure 9 or Table 2.

5. Select the design value using Figures 6 or 7 , and Table 2 .

Where test data are available within a geographical area, use can be made of these data to great advantage. Use can also be made of computers for storage and retrieval of test data. 


\section{REFERENCES}

1. Black, W. P. M., "A Method of Estimating the California Bearing Ratio of Cohesive Soils From Plasticity Data", The Institution of Civil Engineers, 1962.

2. Carey, W. N. Jr. and P. E. Irick, "The Pavement Serviceability Performance Concept," Highway Research Board Bulletin 250, 1960.

3. Bureau of Public Roads (U.S.) "Quality Control and Acceptance Specification: Vol. 1, Quality Control Techniques", Proceedings, Highway Conference on Research Development, 1965.

4. Corps of Engineers, "The California Bearing Ratio Test as Applied to the Design of Flexible Pavements for Airports" U.S. Waterways Experiment Station, Vicksburg, Mississippi, 1945.

5. Hampton, Delon, Eldon J. Yoder and I. W. Burr, "Variability of Engineering Properties of Brookston and Crosby Soils", Proceedings, Highway Research Board, 1962.

6. Road Research Laboratory, "A Guide to the Structural Design of Bituminous-surfaced Roads in Tropical and Sub-tropical Areas", Her Majesty's Stationery Office, London, England, 1966.

7. Road Research Laboratory, "A Guide to the Structural Design of Flexible and Rigid Pavements for New Roads", Her Majesty's Stationery Office, London, England, 1965.

8. Russam, K., "The Distribution of Moisture in Soils at Overseas Airfields," Road Research Technical Paper No. 58, Her Majesty's Stationery Office, London, England, 1962.

9. Turnbull, W. J., C. R. Foster and R. G. Ahlvin, "Design of Flexible Pavements Considering Mixed Loads and Traffic Volume", Proceedings, First International Conference on the Design of Asphalt Pavements, University of Michigan, 1962.

10. Williamson, T. G. and E. J. Yoder, "An Investigation of Compaction Variability for Selected Highway Projects in Indiana". Highra ir Rezearch Riscord $\mathrm{F} ; . \mathrm{i}, 5,2 \mathrm{u} 3$.

11. Woods, K. B. et al, "Highway Engineering Handbook", McGraw-Hill Book Company, 1960.

12. Yoder, Eldon J., "Selection of Soil Strength Values for the Design of Flexible Pavements", Report submitted to the Australian-American Educational Foundation, Canberra, A.C.T., Australia, May, 1968. 


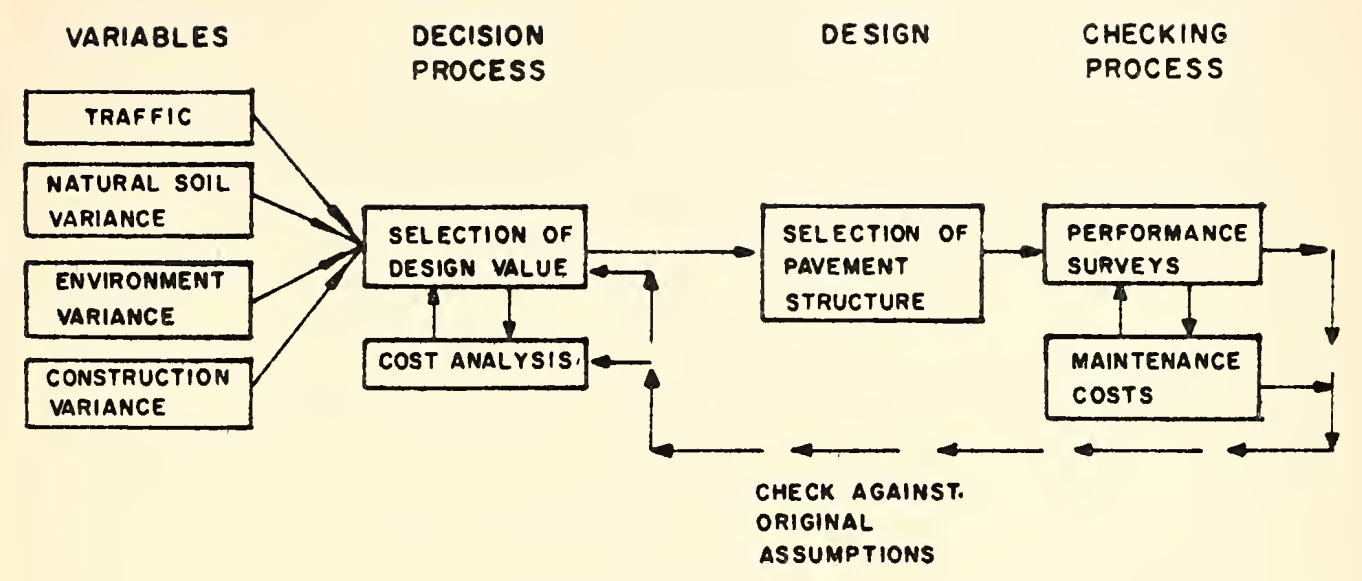

(a) DECISION MAKING PROCESS

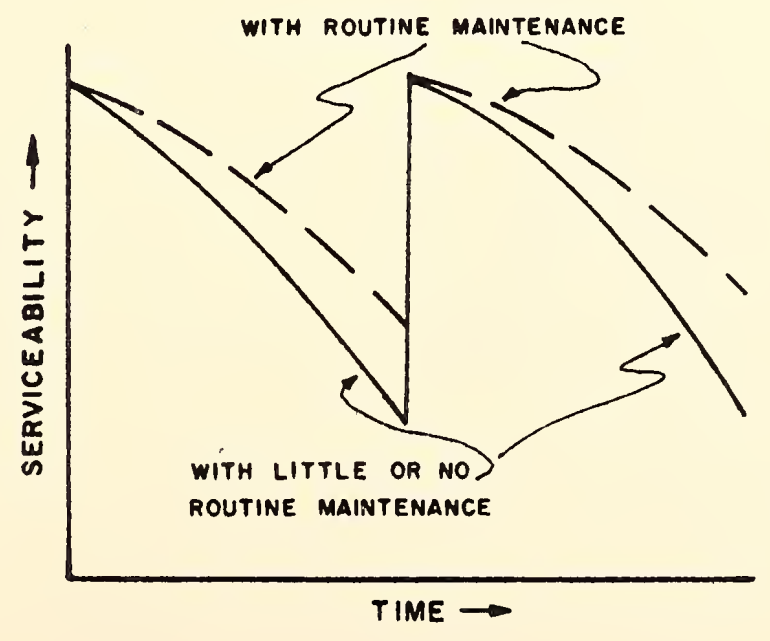

\section{(b) GENERALIZED AELATIONSHIP BETWEEN SERVICEABILITY ANO TIME}

FIG. I. PRINCIPLES INVOLVED IN SELECTION OF DESIGN VALUES 


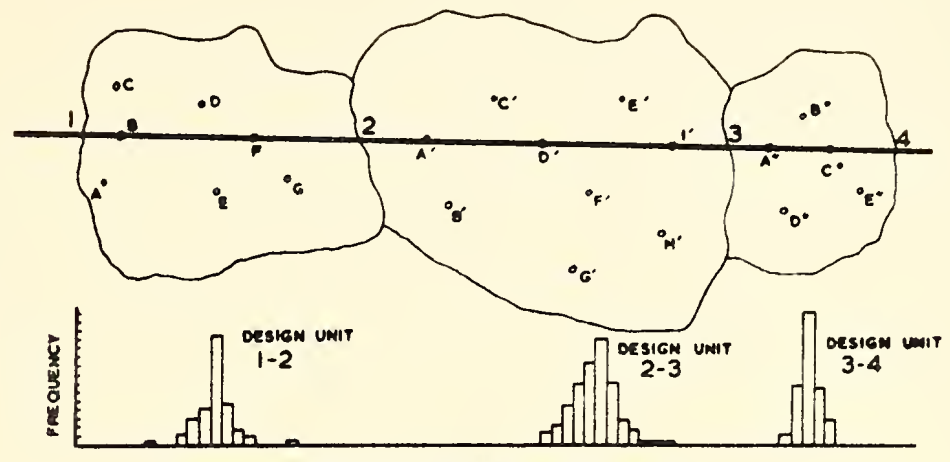

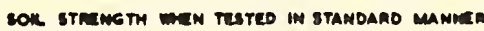

VARIATION ON MATURAL SOIL

(e)

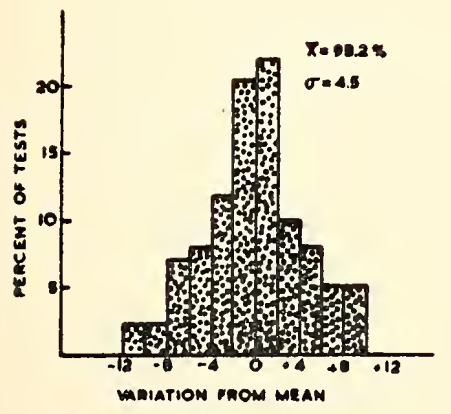
VAMLATION ON PIACENT COMPACTION FON
A BUEGAADE

(b)

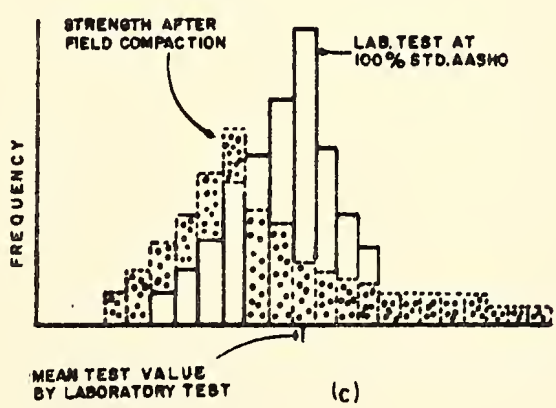

OY LABORATONY TEBT

(c)

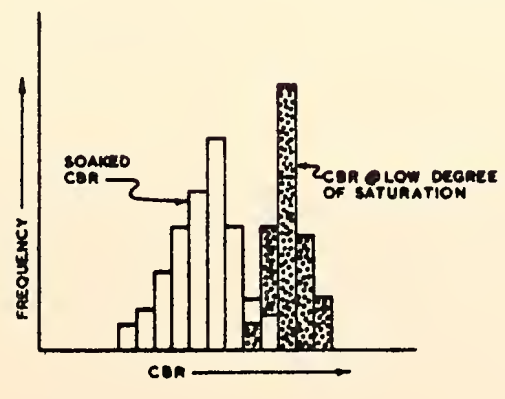

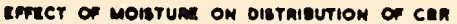

(d) 


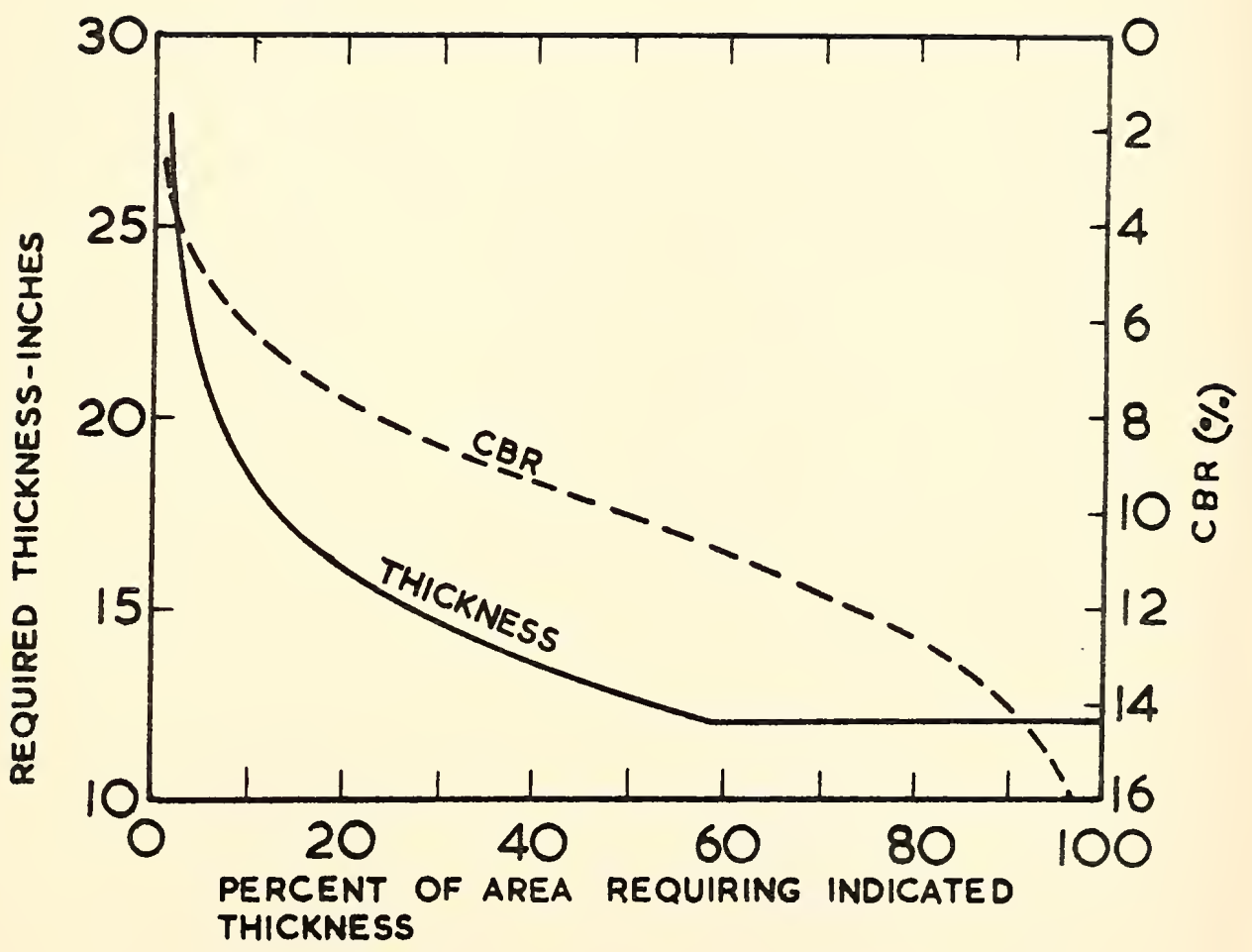

FIG. 3 COMPARISON OF THICKNESS AND CBR VALUES AS A FUNCTION OF SOIL VARIATION. MEAN CBR=10\%, $\sigma=3 \%$ AND INITIAL ADT $=1,000$ vpd. 

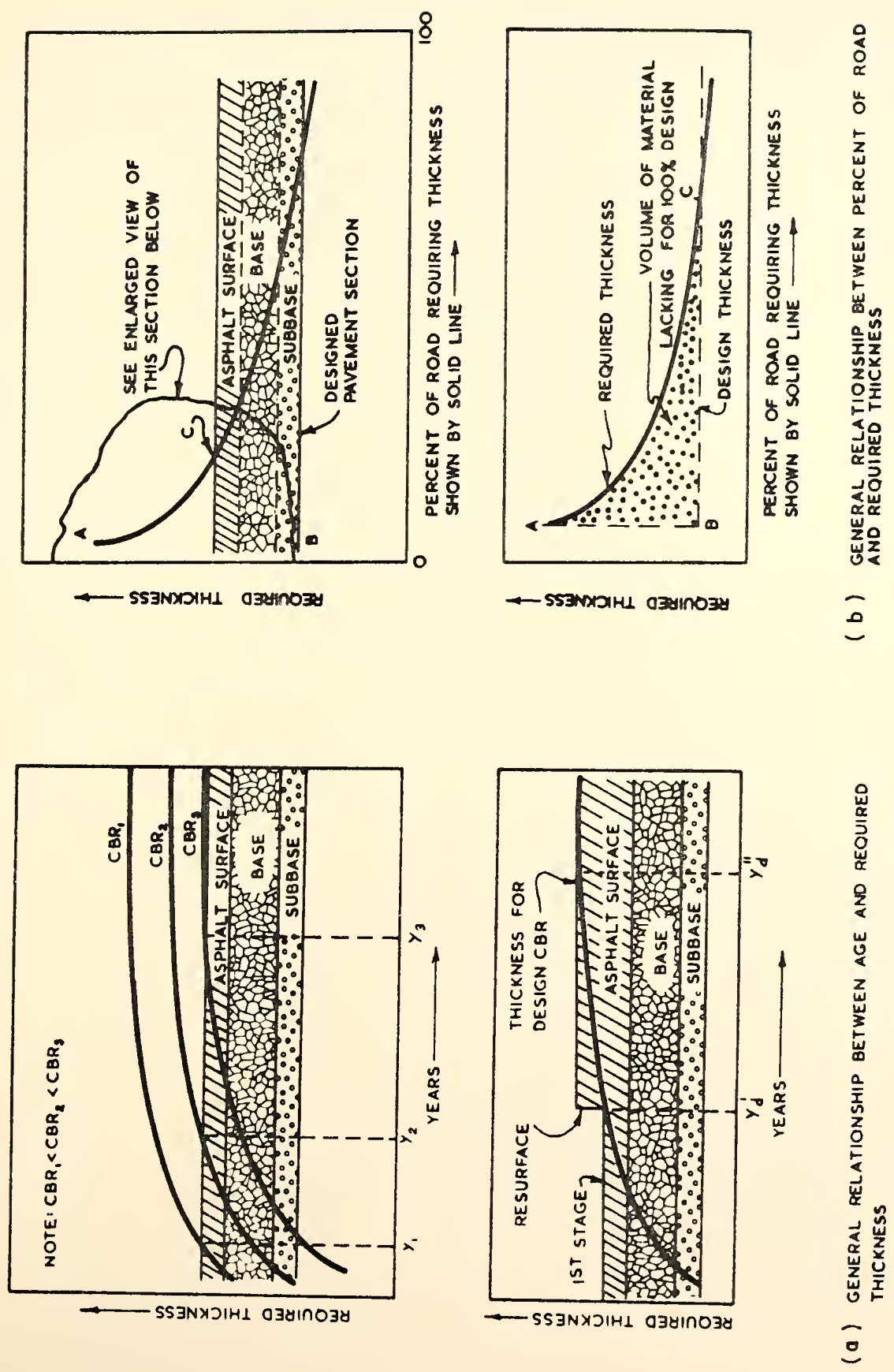


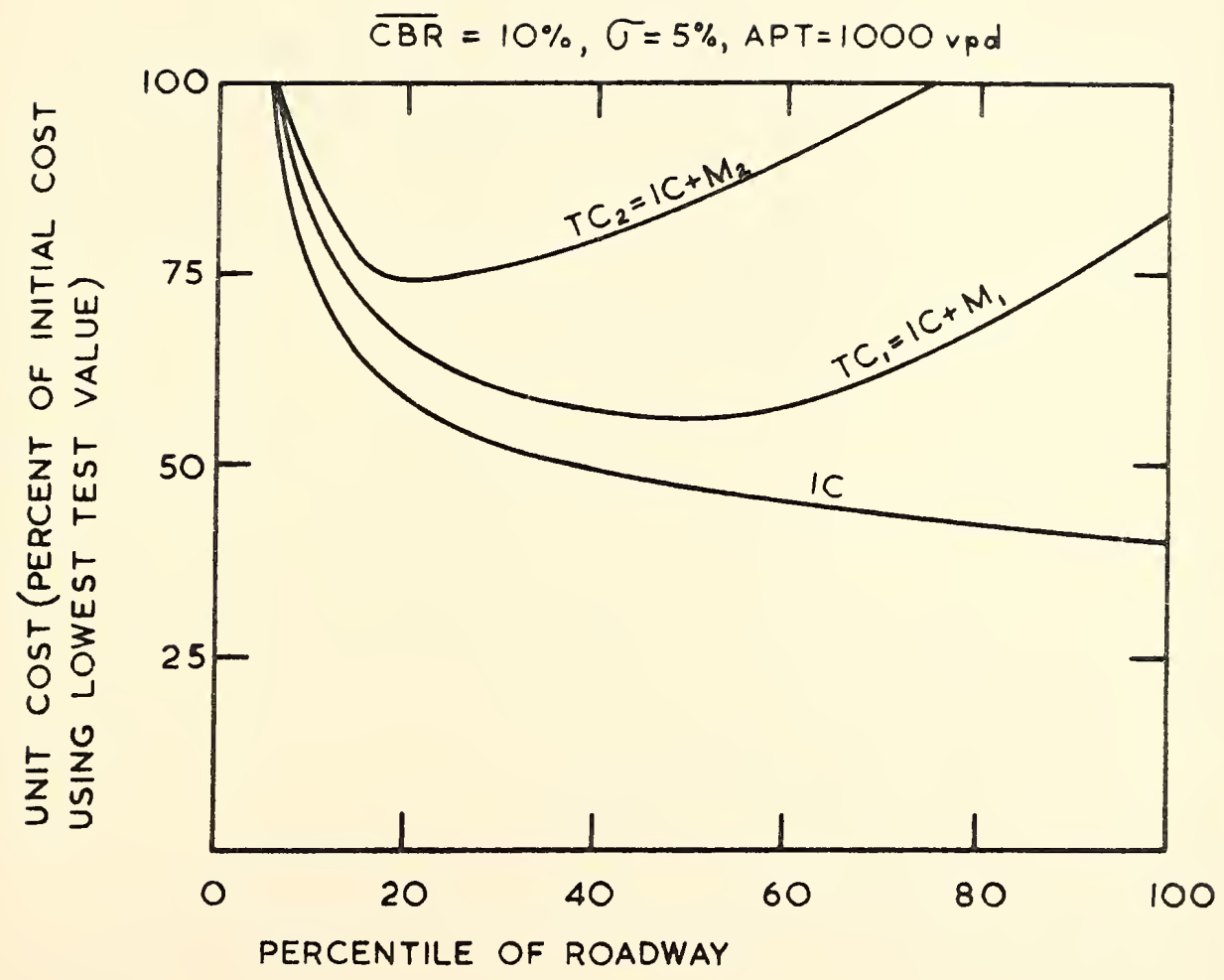

FIG. 5 VARIATION OF INITIAL AND TOTAL COST WITH PERCENTILE ROADWAY 


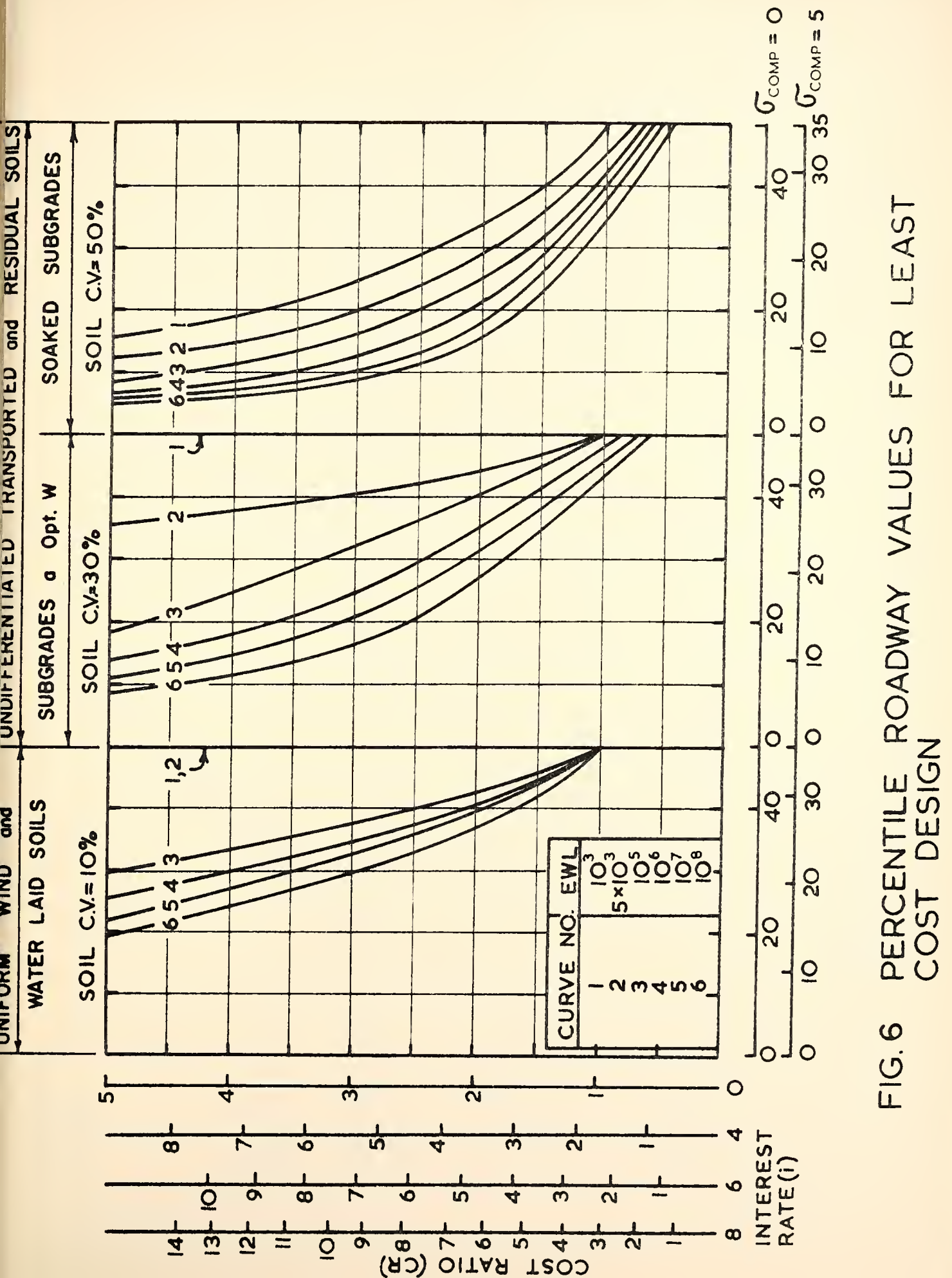




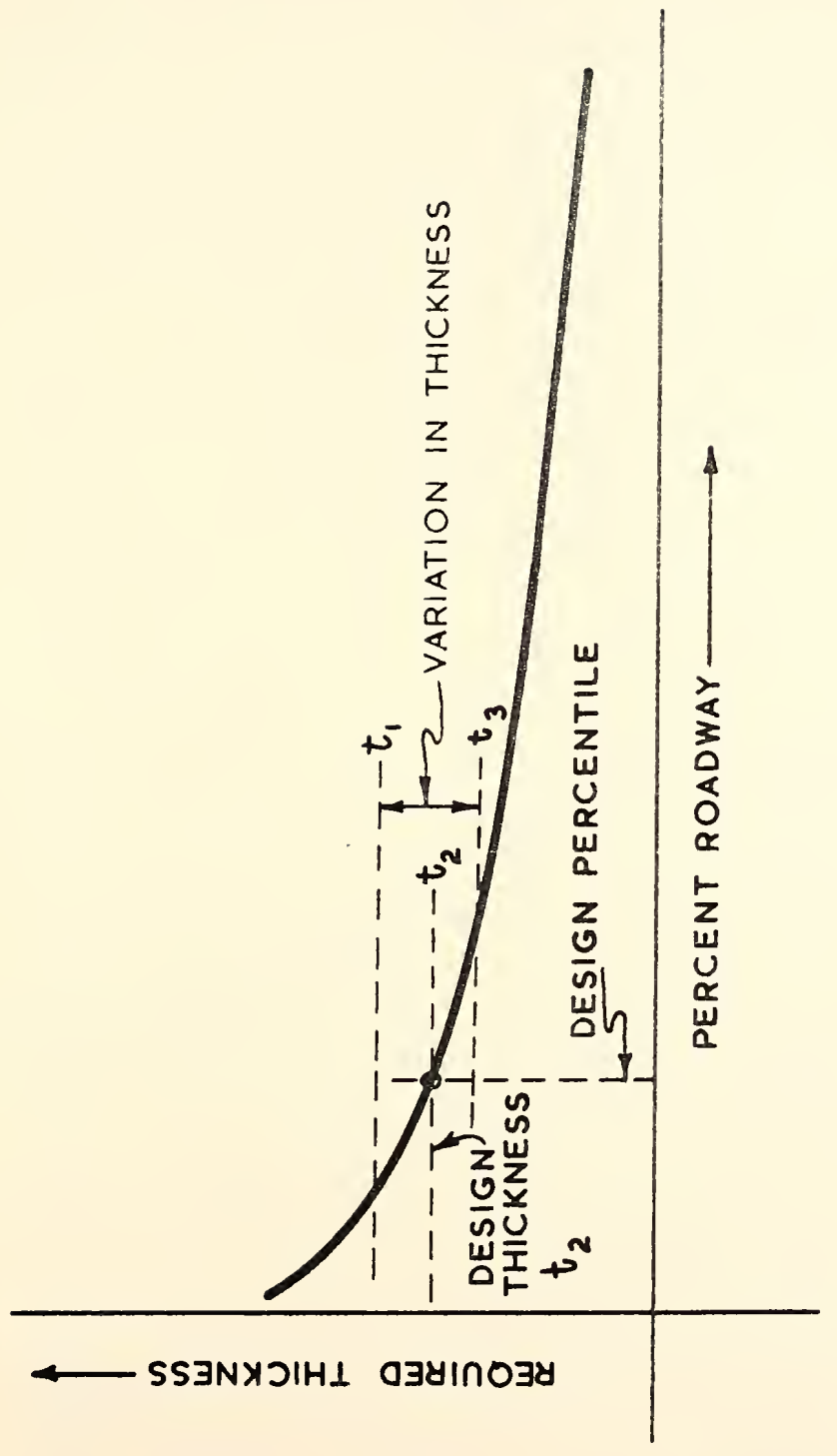

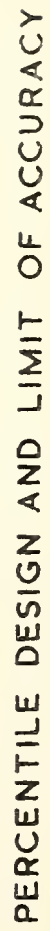

$\frac{0}{u}$ 


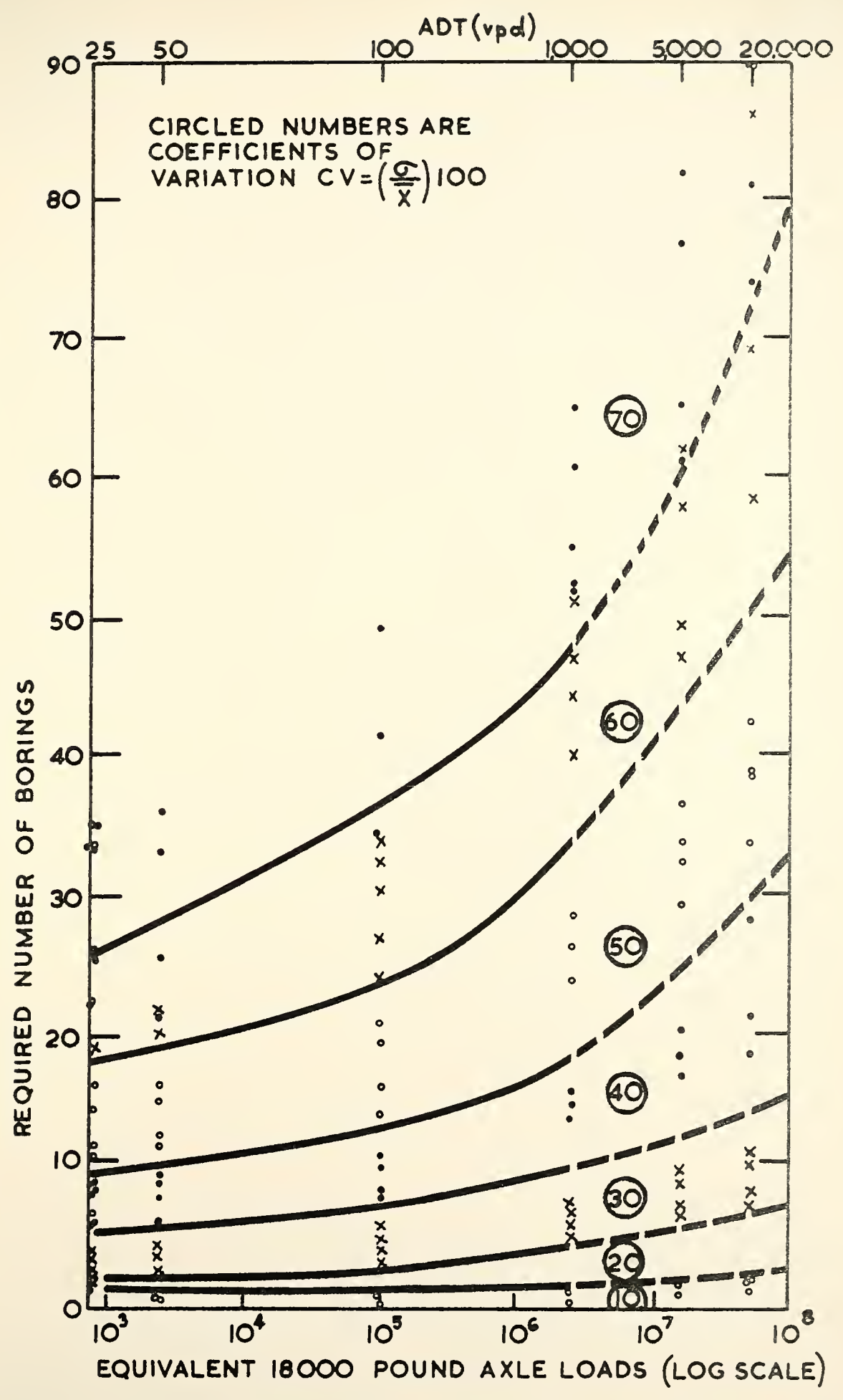

FIG. 9 REQUIRED BORINGS AS A FUNCTION OF TRAFFIC AND SOIL VARIATION 

$F$

i 